\section{Creation of a Preliminary \\ Database for Monitoring and \\ Evaluating the Transformations of \\ the Peri-Urban Landscape of \\ Padua (Italy)}

Gl_Forum 2018, Issue 1

Page: 117 - 125

Short Paper

Corresponding Author:

cgeronta@iuav.it

DOI: 10.1553/giscience2018_01_s117

\author{
Chrysafina Geronta and Viviana Ferrario \\ IUAV University of Venice, Italy
}

\begin{abstract}
This paper discusses the creation of a preliminary database in a GIS environment for the application of indicators measuring features and characteristics of peri-urban agricultural areas of Padua (Italy). Related to the activities of the Interreg Central Europe programme 'UGB - Urban Green Belts', the paper describes a methodology for adapting the European classification system for land cover (CORINE land cover) to a municipal scale for the creation of diachronic, detailed and comparable maps from which a series of further analyses can be carried out, and from which conclusions can be drawn to support urban planning and management of urban green areas. The methodology is discussed in terms of its efficiency to measure as well as graphically represent the dynamics and evolution of the peri-urban landscape of Padua.
\end{abstract}

\title{
Keywords:
}

GIS database, peri-urban landscape, agriculture, CORINE land cover

\section{Introduction}

Contemporary territories that are strongly affected by functional changes due to urbanization processes require new interpretations which take into account globally emerging environmental and socio-economic challenges and technological advances. Within this context, the role of urban and peri-urban agricultural areas becomes significant, as evidenced by their specific characteristics. In the literature, several vulnerabilities of peri-urban agricultural areas are acknowledged, such as the strong competition for resources (mainly land and water), restrictive institutional conditions that limit agricultural production, and the progressive marginalization of agriculture within the socio-economic system (OECD, 1979). Nevertheless, these areas offer significant opportunities and services thanks to the multifunctionality of peri-urban agriculture and the great proximity of the production areas to markets and consumers. Therefore, municipalities are becoming interested in monitoring the transformation of these areas over time and are creating management strategies that 
enhance their role in providing a broad range of ecosystem services to urban dwellers and urbanized areas.

In this context, the Interreg Central Europe programme 'UGB - Urban Green Belts' involved the municipality of Padua (Italy), along with other European municipalities, research centres and development agencies, in developing a pilot model for the governance of public and private green areas from a multifunctional and sustainable perspective. The performance of urban green areas needs to be measured through a set of indicators in a number of pilot areas. In order to implement the pilot model, in addition to the 'conventional' typologies of urban green areas (gardens, parks, street-side trees, outdoor playgrounds, etc.), the municipality of Padua decided to include peri-urban agricultural areas. The governance of such a complex spatial context (Ferrario, 2010) requires tools that can measure agricultural areas as well as represent and communicate their dynamics and evolution efficiently. For this purpose, a database in a GIS environment was required for the application of a subset of indicators measuring features and characteristics of the agricultural zones of the pilot area, as defined in the UGB project (see Table 1).

The Padua pilot area $(2.175 \mathrm{ha})$ covers $23 \%$ of the municipal territory (see Figure 1), extending from the densely built-up city centre to the city limits and beyond. The pilot area was defined by the municipality so as to include as many as possible of the different types of urban green areas, including agricultural land.

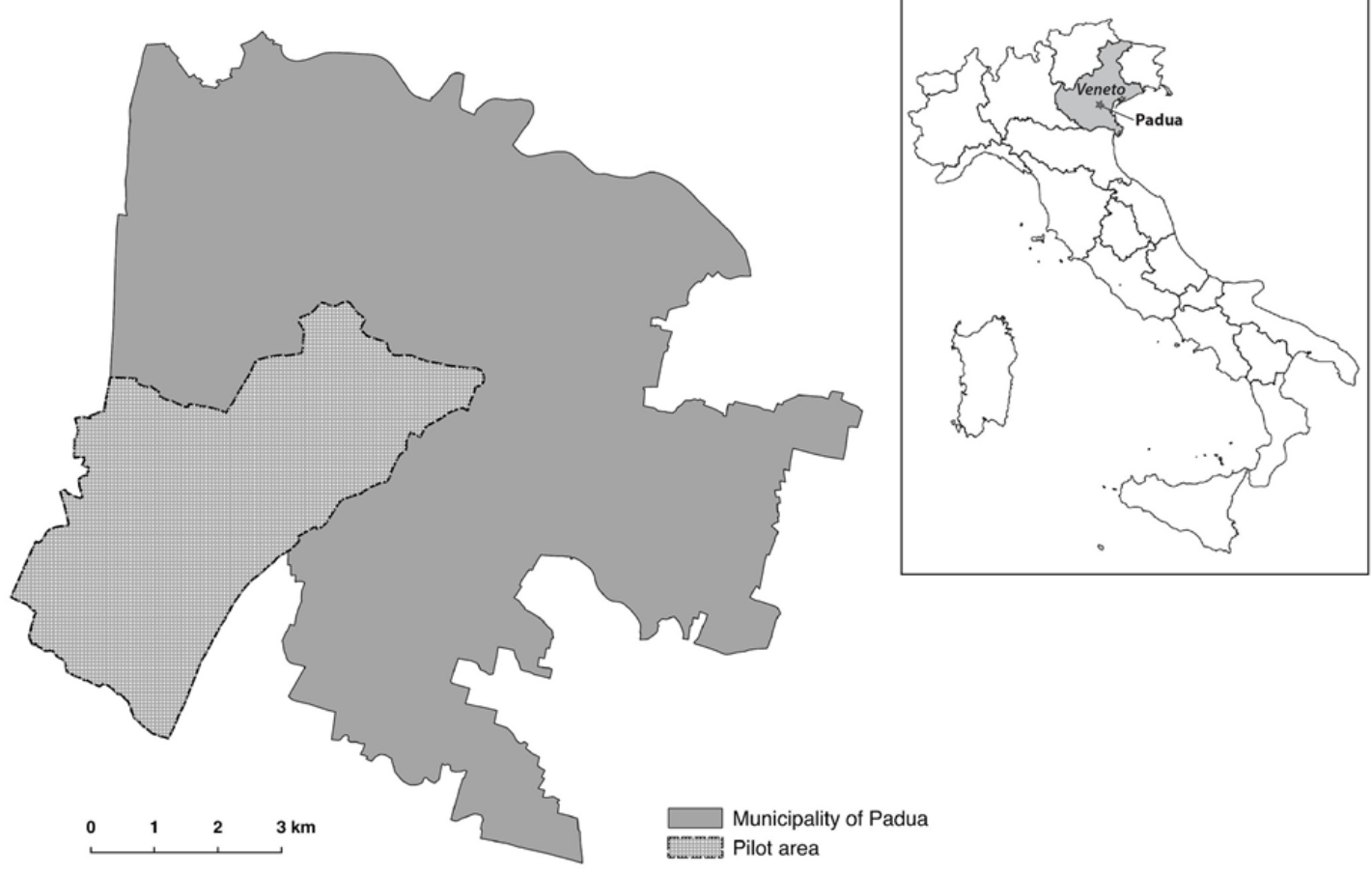

Figure 1: The pilot area of Padua, as defined in the UGB project 
Table 1: Subset of Indicators concerning agricultural areas, as defined in the UGB project (Padua).

\begin{tabular}{|c|c|c|}
\hline \multicolumn{3}{|l|}{ Indicators } \\
\hline \multirow{3}{*}{ Basic } & $\begin{array}{l}\text { B1 } \\
5\end{array}$ & Share of meadows in the agricultural areas $(\%)$ \\
\hline & $\begin{array}{l}\text { B1 } \\
6\end{array}$ & Density of hedges in the agricultural areas (m/ha) \\
\hline & $\begin{array}{l}\text { B2 } \\
2\end{array}$ & Number of farmers' markets and direct-to-consumer points of sale (n) \\
\hline \multirow{2}{*}{$\begin{array}{l}\text { Sustainabili } \\
\text { ty }\end{array}$} & S4 & Number of trees in the agricultural areas ( $\mathrm{n} /$ person) \\
\hline & S13 & $\begin{array}{l}\text { Number of farmers' markets and direct-to-consumer points of sale } \\
\text { (n/person) }\end{array}$ \\
\hline $\begin{array}{l}\text { Attractivene } \\
\text { ss }\end{array}$ & A4 & $\begin{array}{l}\text { Density of historical elements in the agrarian landscape (tree rows, } \\
\text { hedges, farmhouses, wells) ( } \mathrm{n} / \mathrm{ha} \text { ) }\end{array}$ \\
\hline \multirow{3}{*}{ Profitability } & P1 & Share of uncultivated agricultural surface in total agricultural area $(\%)$ \\
\hline & $\mathrm{P} 2$ & $\begin{array}{l}\text { Share of agricultural areas in total public, municipal and private spaces } \\
(\%)\end{array}$ \\
\hline & P3 & Average extent of agricultural patch (ha) \\
\hline
\end{tabular}

In order to define the actual extent and distribution of the agricultural areas, an updated and reliable land-cover map for the entire pilot area was needed. For our purposes, the European CORINE land-cover map was not sufficiently detailed. The CORINE land cover (CLC) project, part of the CORINE programme, ${ }^{1}$ aims to provide support for the development of common policies and provides a common methodology that facilitates the implementation of joint European initiatives. The scale chosen for the project was 1:100.000, as it is a

1 The CORINE programme (COoRdination of Innovation on the Environment) was launched by the Council of the European Communities (Decision 85/338 / EEC) in 1985 to provide the European Union, associated states and neighbouring countries of the Mediterranean and Balkan area with homogeneous information on the state of the environmental and natural resources. 
common mapping scale among European countries and is considered suitable for preliminary investigations for civil development projects or environmental protection.

Given the CLC spatial resolution (minimum mapping unit of 25 hectares), few studies have focused on the use of CLC for analysing urban areas and their evolution. Some authors have reflected on the limited reliability of CLC in applications for local urban dynamics (DíazPacheco and Gutiérrez, 2013) and for representations of spatial phenomena such as dispersed urbanization (Hadjimichalis, 2011), as well as on the need to improve the spatial detail by incorporating land-use/land-cover information in finer thematic maps (Batista et al., 2013).

In this paper, we present and discuss the methodology adopted for the Padua UGB pilot area, ${ }^{2}$ which consists in adapting the CLC classification system to a municipal scale for the creation of detailed and diachronically comparable maps of urban and agricultural peri-urban areas. From these maps, further analyses can be carried out and conclusions can be drawn to support urban planning and the management of urban green areas.

\section{Available data and methodology}

The first methodological step consisted in collecting all available secondary (vector GIS) data and satellite images (orthophotos for the years 2007 and 2017 of $1 \mathrm{~m}$ spatial resolution) for the entire pilot area (see Table 2), which were imported into GIS software and compared rigorously in order to verify any possible conflicts in the data.

A reliable land-cover map based on the CLC classification system (using maximum level 5 of the nomenclature) is available for the entire Veneto region at a scale of 1:10.000 and was used as a starting point for this study. Nevertheless, its spatial detail (minimum mapping unit of $0,25 \mathrm{ha}$ ) was considered insufficient for analysing the dynamics of the peri-urban landscape of Padua, due to some inherent limitations: several agricultural fields are included within the same polygon (small areas of cultivation typical of peri-urban areas do not exceed $0,25 \mathrm{ha}$ ); the presence of buildings dispersed throughout the fields and of other artificial surfaces is generally ignored.

The digital inventory provided by the municipality has a higher degree of spatial resolution, but the classification system is quite complicated for the purposes of this study, as it is composed of many different overlapping layers and the data cover only the year 2007 .

The Italian national cadastral data provide an inventory of land ownership and sporadically updated information about the geometrical and other technical and economic characteristics of parcels (such as land use and income). The cadastral cartography is mainly implemented at a large scale $(1: 2,000)$ at municipal level. The unit size area for cadastral data differs significantly from that of the CLC, as each cadastral parcel represents a single land use and

2 This study is part of a larger research project connected with the UGB Interreg project of the IUAV University of Venice, 'Urban Green Belt: Agro-urban landscape in the metropolitan area of Padova', which started in October 2017 and will run to October 2018, under the supervision of prof. Viviana Ferrario. 
single ownership, and the borders are defined by physical obstacles. The CLC unit size area also makes reference to a homogeneous area of land cover (grass, water, forest, etc.) which is clearly distinguished from the surrounding units. However, its borders do not overlap with those of cadastral units. In the pilot area, a single CLC unit generally includes more than one cadastral unit. In fewer cases, cadastral units are separated by the CLC unit boundary.

Table 2: Secondary available data

\begin{tabular}{|l|l|l|l|}
\hline Data source & Available vector data & Scale & Time reference \\
\hline Veneto Region & Land-cover map & $1: 10,000$ & 2007,2012 \\
\hline $\begin{array}{l}\text { Municipality of } \\
\text { Padua }\end{array}$ & $\begin{array}{l}\text { Digital inventory of green and } \\
\text { agricultural areas and related trees }\end{array}$ & $1: 5,000$ & 2007 \\
\hline $\begin{array}{l}\text { Cadastral } \\
\text { office of } \\
\text { Padua }\end{array}$ & $\begin{array}{l}\text { Cadastral map with land-cover } \\
\text { attribute for each parcel }\end{array}$ & $1: 2,000$ & $\begin{array}{l}\text { Not homogeneous } \\
\text { updated } \\
\text { sporadically) }\end{array}$ \\
\hline
\end{tabular}

For the purposes of this study, the cadastral data was deemed the most appropriate in terms of the spatial resolution of the geometrical features, but it had to be integrated with the more reliable and comparable regional land-cover data.

To do this, a preliminary distinction between agricultural and urban parcels was necessary. Overlaying the cadastral vector map with the regional land-cover map (2007), we obtained a topographical selection for all the cadastral parcels with agricultural land cover included in the polygons. A value of 1 was attributed to the selected parcels (agricultural land cover), while value 0 was attributed to the rest of the parcels (non-agricultural land cover). The attribution of the values was corrected after verifying their validity by means of a visual interpretation of the orthophotos (for the year 2007). This process allowed the exclusion of parcels with a significant percentage of artificial surfaces, and a precise distinction between agricultural and urban land was achieved.

Once the actual extent and distribution of the agricultural areas for the year 2007 had been defined, the next methodological step consisted in the attribution of a specific CLC nomenclature (3rd level) to each cadastral parcel, obtained by comparing the land-cover nomenclature attributed in the regional data with the orthophoto for each parcel. Where a parcel included more than one land-cover type (i.e. arable land, vineyards, other permanent cultivation), the class 242 for complex cultivation patterns was attributed (see Figure 3).

Because of the lack of regional data for the year 2017, the final step consisted in classifying the cadastral parcels according to CORINE land cover by visual interpretation, using the orthophotos for the year 2017. 


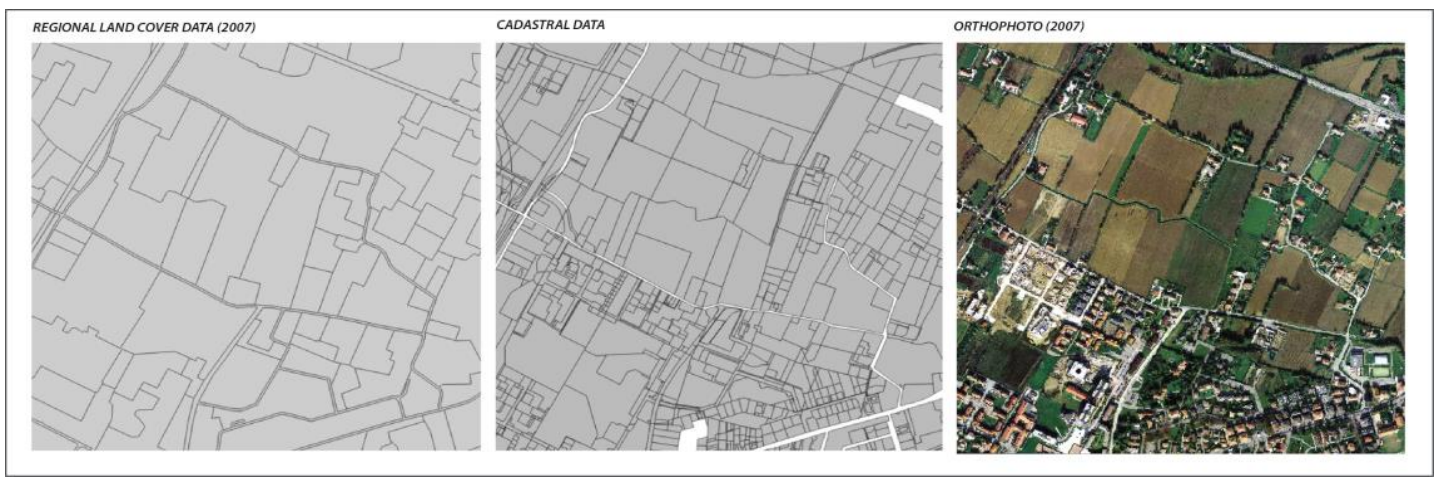

Figure 2: Comparison of the spatial resolution of available vector data and orthophoto

\section{The new database and its reliability}

Following the methodological steps described above, a new shapefile was created using the geometrical features of the cadastral parcels and their existing identification attributes, along with new fields for attributes corresponding to CLC information for the years 2007 and 2017 (see Table 3).

The result is a new database that harmonizes and integrates existing data along with new data. As new data is produced through the conventional visual interpretation of satellite images and by recoding nomenclatures, both processes that involve subjective judgements, the reliability of the database was subjected to further evaluation.

In the peri-urban context, this modelling of geographical data presents an alternative to the Land Parcel Identification System (LPIS), as it provides information for all agricultural parcels, not just those eligible for annual payments of European Common Agricultural Policy (CAP) subsidies to farmers. Moreover, the small size and pattern of the agricultural units characterizing the peri-urban landscape render cadastral parcels appropriate for use as reference parcels. Indeed, in this study, the majority of cadastral parcels correspond to a single crop and a single farmer, and the cadastral parcels that do not correspond to particular agricultural patterns are limited in number. For the latter, in order to improve the accuracy of the modelling, the cadastral parcel can be divided into sub-parcels of different types of land cover. In addition, this modelling attempts to address the issue of outdated land-cover information from cadastral data by using specific time references for each land-cover attribution.

The creation of the new database thus provides a reliable quantification of peri-urban agricultural areas and a platform for the evaluation of transformations over time. The results show that agricultural areas occupy a significant proportion of the Padua pilot area $(32,7 \%$ of the area in 2017) and are concentrated in the south especially, between the Bacchiglione river and the municipality's administrative borders. Nevertheless, a considerable concentration of agricultural land can also be found in the northern part of the pilot area, near the city centre itself. Comparison of the total extents of agricultural land in 2007 and 2017 shows that in this 10 -year period there was a $6.5 \%$ reduction in agricultural land. This loss is due to new 


\section{Geronta et al}

road construction, some new housing developments, the construction of sports facilities and the installation of a photovoltaic plant.

Table 3: List of field attributes for each feature (cadastral parcel)

\begin{tabular}{|l|l|l|l|}
\hline \multicolumn{2}{|l|}{ Existing fields } & \multicolumn{2}{l|}{ New fields created } \\
\hline id & Feature number & agr 2007 & $\begin{array}{l}\text { Distinction between agricultural and urban parcels } \\
\text { for the year 2007 (agricultural land cover } 1 \text {, non- } \\
\text { agricultural land cover }=0,-999 \text { outside pilot area) }\end{array}$ \\
\hline $\begin{array}{l}\text { codic_ide } \\
\text { n }\end{array}$ & Parcel number & $\begin{array}{l}\text { CLCcod20 } \\
07\end{array}$ & $\begin{array}{l}\text { CLC nomenclature code (3rd level) for the year } \\
2007\end{array}$ \\
\hline comune & $\begin{array}{l}\text { Name of } \\
\text { municipality }\end{array}$ & CLC2007 & $\begin{array}{l}\text { CLC nomenclature label (3rd level) for the year } \\
2007\end{array}$ \\
\hline fg_map & Map number & agr 2017 & $\begin{array}{l}\text { Distinction between agricultural and urban parcels } \\
\text { for the year 2017 (agricultural land cover }=1, \text { non- } \\
\text { agricultural land cover }=0,-999 \text { outside pilot area) }\end{array}$ \\
\hline foglio & Sheet number & $\begin{array}{l}\text { CLCcod20 } \\
17\end{array}$ & $\begin{array}{l}\text { CLC nomenclature code (3rd level) for the year } \\
2017\end{array}$ \\
\hline sezione & Section number & CLC2017 & $\begin{array}{l}\text { CLC nomenclature label (3rd level) for the year } \\
2017\end{array}$ \\
\hline
\end{tabular}




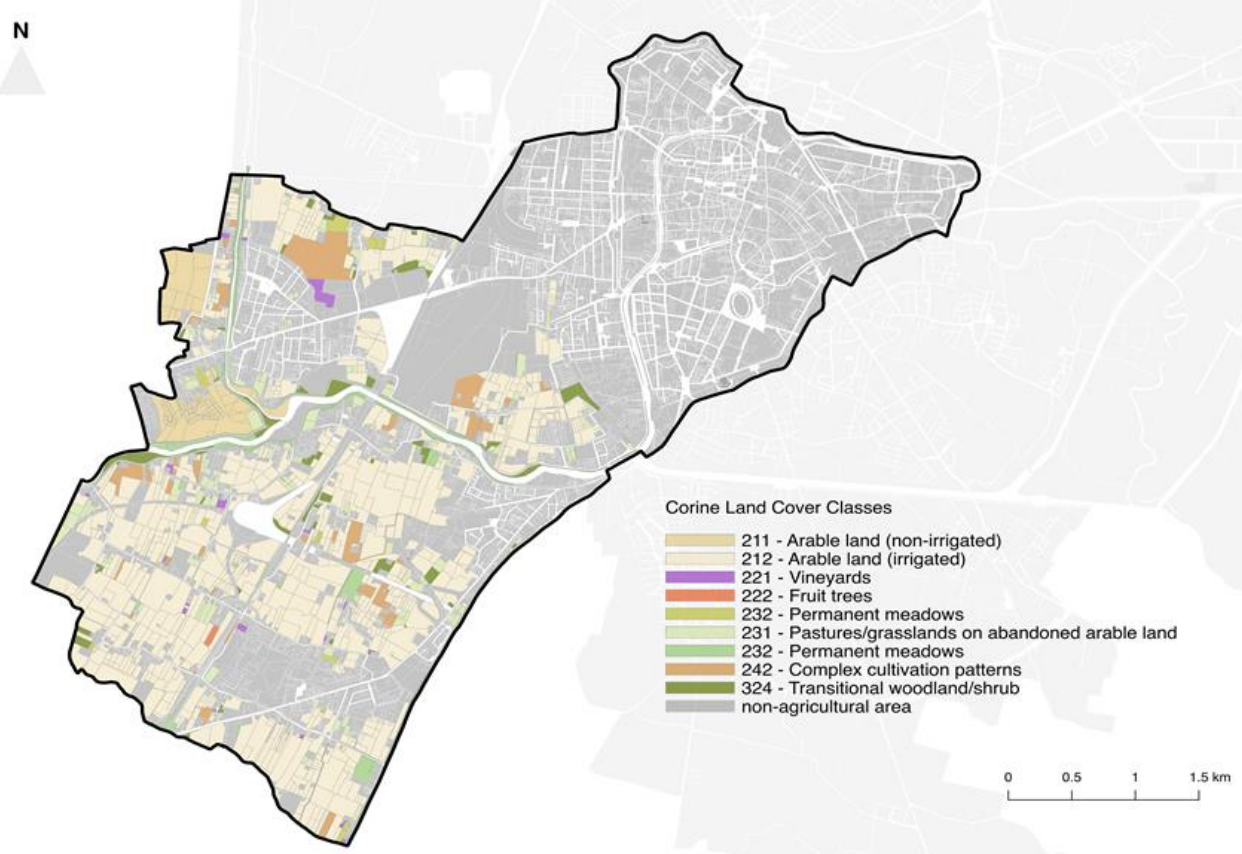

Figure 3: Land cover of the agricultural areas based on cadastral data for the year 2017
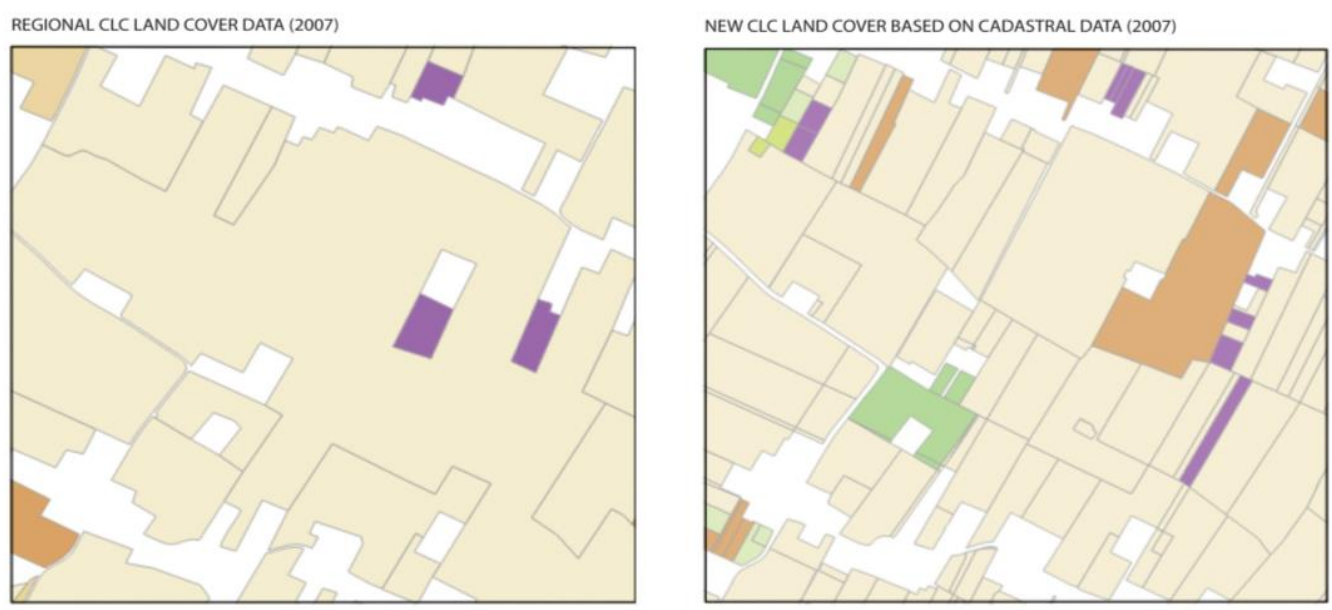

Figure 4: Comparison between the regional land-cover data and the new database

\section{Conclusions}

This study focused on a methodology for adapting the European classification system of land cover (CORINE land cover) to a municipal scale using cadastral data, in order to 
respond to the need for diachronic, detailed and comparable maps as a basis for further analyses related to the management of urban green areas.

Land-cover maps produced using cadastral data provide greater spatial detail of land cover allowing features of the peri-urban landscape to be measured with more accuracy. They also give a more appropriate visual representation of the local dynamics, as small but significant changes that occur at a local level may help local administrative bodies to predict greater transformation trends in the peri-urban landscape and to evaluate their impacts.

The visual representation of the local dynamics of the peri-urban landscape may also help highlight the responsibilities of landowners as regards the changes in land use and land cover of their properties. Finally, the new database based on CLC maintains homogeneity and interoperability with other regional and interregional projects.

\section{References}

Batista F, Batista S, Lavalle C, Koomen E. (2013). A procedure to obtain a refined European land use/cover map. Journal of Land Use Science Vol. 8 (3)

Díaz-Pacheco J, Gutiérrez J. (2013). Exploring the limitations of CORINE land cover for monitoring urban land use dynamics in metropolitan areas. Journal of Land Use Science Vol. 9 (3), 243-259.

Duvernoy, I., Zambon, I., Sateriano, A., Salvati, L. (2018). Pictures from the other side of the fringe: Urban growth and peri-urban agriculture in a post-industrial city (Toulouse, France) Journal of Rural Studies, 57, 25-35.

EEA. (2000). CORINE Land Cover technical guide - Addendum 2000 (Technical Report No. 40). Copenhagen: EEA.

EEA, Eurostat, DG Agriculture, DG Environment, and Joint Research Center. (2001). Towards agrienvironmental indicators: Integrating statistical and administrative data with land cover information. Copenhagen: EEA.

Ferrario V. (2010). About agricultural space in the città diffusa and its importance for the future, in Viganò P., Fabian L. (eds), Extreme city. Climate change and the transformation of the waterscape, Padova: Il Poligrafo

Grandgirard D., Zielinski, R. (2008). Land Parcel Identification System (LPIS) Anomalies'Sampling and Spatial Pattern: Towards convergence of ecological methodologies and GIS technologies, EUR 23484 EN - Joint Research Centre - Institute for the Protection and Security of the Citizen.

Hadjimichalis K. (ed.), (2011). Contemporary Greek Landscapes (Geographical approach), Athens: Melissa (in Greek).

OECD. (1979). Agriculture in the Planning and Management of Peri-urban Areas, Paris.

Serra P., Sauri D., Salvati L. (2017). Peri-urban agriculture in Barcelona: outlining landscape dynamics vis à vis socio-environmental functions. Landscape Research, DOI: 10.1080/01426397.2017.1336758

Turner, B. (2001). Land-use and land-cover change: Advances in 1.5 decades of sustained international research. GALA, 10, 269-272.

Zhou, Z., Li, M. (2017). Spatial-temporal change in urban agricultural land use efficiency from the perspective of agricultural multi-functionality: A case study of the Xi'an metropolitan zone. Journal of Geographical Sciences 27, (12), 1499-1520. 